\title{
An Experimental Study on Characteristics of Impact Compression of Freeze-Thawed Granite Samples Under Four Different States Considering Moisture Content and Temperature Difference
}

Chunyang Zhang ( $\nabla$ zcl2722@163.com )

Wuhan University of Technology

\section{Bo Ke}

Wuhan University of Technology

Chuanju Liu

Southwest University of Science and Technology

Linmin Ding

Changsha Institute of Mining Research Co., Ltd

\section{Yixian Wang}

Hefei University of Technology

Hang Lin

Central South University

\section{Research Article}

Keywords: Granite samples, Freeze-thaw cycles, Impact compression test, Impact strength, Dynamic elastic modulus, Freeze-thaw influence factor

Posted Date: April 19th, 2021

DOI: https://doi.org/10.21203/rs.3.rs-404549/v1

License: (c) (1) This work is licensed under a Creative Commons Attribution 4.0 International License. Read Full License 


\section{An experimental study on characteristics of impact} compression of freeze-thawed granite samples under four different states considering moisture content and temperature difference

${ }^{\text {a }}$ School of Resources and Environmental Engineering, Wuhan University of Technology, Wuhan 430070, China

b School of Environment and Resource, Southwest University of Science and Technology, Mianyang 621010,

\section{China}

c Changsha Institute of Mining Research Co., Ltd, Changsha 410012, China

d State Key Laboratory of metal mine safety technology, Changsha 410012, China

e School of Civil Engineering, Hefei University of Technology, Hefei 230009, China

f School of Resources and Safety Engineering, Central South University, Changsha 410083, China

Abstract: The mechanics of rock masses in cold regions have attracted the attention of researchers from all over the world, and the concern here is that the mechanical properties of rock masses are inevitably weakened under freeze-thaw cycles. In this paper, firstly, granite samples were subjected to different freeze-thaw cycles, after that, we dealt with the freeze-thawed samples considering four different states, such as saturated and frozen states, saturated and normal temperature states, dry and frozen states as well as dry and normal temperature states. The impact compression test was carried out by using the Split Hopkinson Pressure Bar (SHPB) device. Results show that the impact strength of granite samples deteriorates with the increase of freeze-thaw cycles in the same state, for samples in different states, although the number of freeze-thaw cycles is equal, the degree of deterioration of 
the impact strength is different. For freeze-thawed granite samples in the same state, the dynamic elastic modulus decreases with the increase of freeze-thaw cycles, and its degree of decrease is different for different states. Under the same freeze-thaw cycles, the deterioration of mechanical properties of granite samples is different in four different weather states, for example, the dynamic elastic modulus from large to small is generally as follows: saturated and frozen states, saturated and normal temperature states, dry and frozen states as well as dry and normal temperature states. Finally, the freeze-thaw influence factor is proposed to describe the damage of granite samples. All in all, it can be concluded that water and low temperature strengthen the influence of freeze-thaw cycles on the dynamic mechanical properties of granite samples.

Keywords: Granite samples; Freeze-thaw cycles; Impact compression test; Impact strength; Dynamic elastic modulus; Freeze-thaw influence factor

\section{Introduction}

Rockmass stability, on the one hand, depends on the geological conditions and mechanical properties (Cao et al. 2020c; Zhao et al. 2020b; Zheng et al. 2020b; Lin et al. 2020a), on the other hand, is affected by variable external conditions, such as water (Zhang et al. 2020a), temperature (Deprez et al. 2020a), external load (Lin et al. 2020c), etc. As an example, freeze-thaw (FT) weathering deteriorates the mechanical properties of rock masses in areas where the temperature periodically fluctuates around the freezing point (Deprez et al. 2020). Kellerer-Pirklbauer (2017) considered that freeze-thaw cycles and effective freeze-thaw cycles for frost shattering are mainly affecting near-surface rock masses; Langman et al. (2017) found that the fluctuation of the freeze-thaw cycle caused the greatest sulfide weathering near the surface. However, $\mathrm{Xu}$ et al. (2019) pointed out that the instability of rock slope in the freeze-thaw mountains has abrupt and 
uncertain characteristics, and its prediction accuracy often is very low. Therefore, considering the complexity of freeze-thaw process of rock masses in cold regions, the achievements are mainly based on indoor experiments rather than field experiments.

It is well known that the mechanical properties of rock masses are inevitably affected after repeated freeze-thaw cycles, and many achievements have verified this statement. Ke et al. (2020) declared that the dynamic Young's modulus and peak stress first increase and then decrease with increasing axial pre-compression stress at the same number of freeze-thaw cycles; Lu et al. (2021) stated that the strength variation law established by the single discontinuity theory is in good agreement with the uniaxial and triaxial test results; Sinclair et al. (2015) reported that the northern waste rock pile drainage geochemistry is strongly influenced by freeze-thaw cycling; Shen et al. (2020) concluded that the F-T cycles have a significant effect on the bonding performance of concrete-granite interface caused by the deterioration effects of cementation; Hashemi et al. (2018) verified that the ultrasonic parameters of maximum amplitude, spatial attenuation, and compressional wave velocity were changed after freeze-thaw tests; Cao et al. (2020a) found that the fracture paths of the SCB specimens subjected to F-T treatments are more tortuous than those in specimens without F-T treatment.

Generally speaking, the mechanical properties of rocks are gradually weakened with the increase of freeze-thaw cycles. For example, an increase in porosity and decrease in $\mathrm{P}$ wave velocity demonstrated a degradation in physical properties after F-T cycles (Zhang et al. 2019); The high porosity and weakening of bonds between the carbonate grains is reflected in the very low tensile strength values obtained after 10 freeze-thaw cycles (Pápay and Török, 2015); The freeze-thaw damage grows quickly with increasing saturation and freeze-thaw cycles after 
exceeding the critical saturation (Liu et al. 2020c); Compared to fresh specimens, red-sandstone after $10 \mathrm{~F}-\mathrm{T}$ cycles performs poorly in both the static compression and SHPB impact tests (Wang et al. 2016); The long-term strength of red sandstone presents apparent decreasing trends with an increase in the F-T temperature range (Wang et al. 2021a); The Uniaxial Compression Strength of rocks decreases significantly with the increase of moisture content during F-T cycles ( $\mathrm{Li}$ et al. 2020); The freeze-thaw cycle progression led to decreases in point load strength, Schmidt hardness, and weight and an increase in porosity of the specimens (Sarici and Ozdemir, 2018); The mechanical parameters of sandstone had a significant damage deteriorating trend under freeze-thaw cycles (Han et al. 2020); The tangent modulus, total input strain energy, releasable elastic strain energy and dissipated energy of samples decrease with the increase of F-T cycles (Deng et al. 2019); F-T treatment decreases both fatigue strength and strain energy of marble (Wang et al. 2021b); Lin et al. (2020b) considered that the deterioration of jointed rock masses is mainly due to the frost heaving pressure. All in all, the weakening law of mechanical properties of rock masses in cold regions is helpful to analyze the damage mechanism and prevent disasters.

At present, the study of rock mechanics in cold regions has gradually become one of the hot topics, and the application of new technologies and means promotes its development, such as Nuclear Magnetic Resonance (NMR) technology (Ding et al. 2020; Zhou et al. 2015; Liu et al. 2021; Jia et al. 2020; Liu et al. 2020a; Pan et al. 2020; Zhang et al. 2020d; Liu et al. 2020b;), Ultrasonic Detections (Ding et al. 2020; Wang et al. 2017; Çelik, 2020; Wang et al. 2019; Ivankina et al. 2020), Digital Image Correlation (DIC) (Mardoukhi et al. 2021), Neutron Diffraction Measurements (Ivankina et al. 2020), Scanning Electron Microscope (SEM) (Wang et al. 2017; Çelik, 2020; Wang et al. 2019; Chang et al. 2020; Abdolghanizadeh et al. 2020; Fang et al. 2018; 
Zhou et al. 2018; Yang et al. 2021b; Zhou et al. 2019; Zhao et al. 2019), Computed Tomography (CT) technique (Wang et al. 2020b), Optical Microscope (Çelik, 2020; Mousavi et al. 2020), X-ray Computed Micro-tomography (Deprez et al. 2020b), X-ray diffraction (XRD) (Zhao et al. 2019; Mousavi et al. 2020), Acoustic Emission (Wang et al. 2020b; Xiao et al. 2020), Infrared thermography (Yang et al. 2021a). These new techniques and their combined applications help to discover new features in experiments and provide verification means for the development of theory or numerical simulation.

Theory and numerical simulation are also important means in the study of rock mechanics (Cao et al. 2020b; Zhao et al. 2020a; Zheng et al. 2020a). For freeze-thaw damage of rocks, Zhang et al. (2020e) presented an analytical solution for the frost heaving force based on complex variable theory and the power series method; A model describing the dynamic increase factor for the dynamic rock strength corresponding to different strain rates and specimen sizes was given by Ke et al. (2018); Zhang et al. (2020b) derived an elasto-visco-plastic model based on stress functions to describe deformation and damage of water-saturated rocks during the freeze-thaw process; Zhang et al. (2020c) established a damage model which can reflect the characteristics of postpeak strain softening and residual strength; Chen et al. (2020) derived the damage evolution equation of fractured rock; Huang et al. (2020) proposed a novel elastoplastic model to estimate the long-term frost heave and frost damage. In the aspect of numerical simulation, Pu et al. (2020) analyzed the dynamic compressive strength and dynamic elastic modulus of sandstone based on LS-DYNA; Lin et al. (2020a) established a 3D model considering moisture migration loss to study the characteristics of frost heaving force within joints.

To make a long story short, the above-mentioned achievements provide a reference for the 
111

112

113

115

116

117

119

study of this paper. Here we first carried out the damage experiments of granite samples under freeze-thaw cycles, after that, considering the actual situation of rock masses in high altitude area, especially the different states caused by seasonal changes, the impact compression characteristics of freeze-thawed granite samples are studied under four different states, such as moisture content and temperature difference. It should be noted that no similar studies have been reported so far.

\section{The principle of SHPB device}

As shown in Fig. 1, the Split Hopkinson Pressure Bar (SHPB) device is mainly composed of gas gun, striker, incident bar, gauge, transmitted bar, momentum bar, et al. In the impact test, the rock sample is placed between the incident bar and the transmitted bar, after adjusting the position and setting the impact pressure, the incident bar is impacted by the pressure released from the gas gun to produce one-dimensional stress wave acting on the sample.

It is assumed that the SHPB device conforms to the mechanical characteristics of one-dimensional bar, then two conditions need to be met during the process of P-wave propagation, that is to say, the cross section of the rod before and after deformation is plane, and the axial force in the rod is evenly distributed. Dynamic mechanical parameters of specimens can be calculated indirectly by the measured voltage in strain gauge in test: stress $\sigma_{s}$, strain $\varepsilon_{s}$ and strain rate $\stackrel{\mathrm{g}}{\mathcal{E}_{s}}$, which can be expressed as follows (Xie et al. 2014; Wang et al. 2020a; Hassan and Wille, 2017; Jia et al. 2021):

$\sigma_{s}=\frac{P_{1}+P_{2}}{2 A_{0}}=\frac{A E}{2 A_{0}}\left[\varepsilon_{i}+\varepsilon_{r}+\varepsilon_{t}\right]$

$\varepsilon_{s}=\frac{\mu_{1}-\mu_{2}}{l_{0}}=\frac{c_{0}}{l_{0}} \int_{0}^{t}\left[\varepsilon_{i}-\varepsilon_{r}-\varepsilon_{t}\right] d t$ 
134 where $A, E$ are cross-sectional area and Young's modulus of pressure bar, respectively; $A_{0}$, $135{ }^{l}{ }_{0}$ are cross-sectional area and length of granite samples, respectively; $\varepsilon_{i}, \varepsilon_{r}, \varepsilon_{t}$ are the incident strain signal, reflected strain signal and transmitted strain signal, respectively; $c_{0}$ is the P-wave velocity in the pressure bar; $v_{1}, v_{2}$ are the velocities at the incident and transmitted specimen faces, respectively; $P_{1}, P_{2}$ are the forces at the incident and transmitted faces,

139 respectively; $C_{0}$ is the one dimensional longitudinal stress wave velocity of the bar.

$$
\left\{\begin{array}{c}
v_{1}=c_{0}\left(\varepsilon_{i}-\varepsilon_{r}\right) \\
v_{2}=c_{0} \varepsilon_{t}
\end{array}\right.
$$

$$
\left\{\begin{array}{c}
P_{1}=A E\left(\varepsilon_{i}+\varepsilon_{r}\right) \\
P_{2}=A E \varepsilon_{t}
\end{array}\right.
$$

$$
\left\{\begin{array}{c}
\mu_{1}=c_{0} \int_{0}^{t}\left(\varepsilon_{i}-\varepsilon_{r}\right) d t \\
\mu_{2}=c_{0} \int_{0}^{t} \varepsilon_{t} d t
\end{array}\right.
$$

\section{Sample preparation and test plan}


152

153

polished to ensure that the parallelism of the upper and lower surfaces is less than $0.05 \mathrm{~mm}$, the flatness of the surface is less than $0.02 \mathrm{~mm}$, the end face is perpendicular to the axis of the sample, and the maximum deviation is not more than 0.25 degrees, typical samples are shown in Fig. 2.

Granite samples are saturated by a vacuum saturator, then frozen for $4 \mathrm{~h}$ in a thermostat held at $-30{ }^{\circ} \mathrm{C}$, finally, the temperature is raised to $20^{\circ} \mathrm{C}$ and maintained for $4 \mathrm{~h}$ to ensure that samples are completely thawed, thus a freeze-thaw cycle is completed. The number of freeze-thaw cycles determined in this paper is $0,30,60,90$ and 120 , respectively. Considering the actual situation of rock masses in high altitude area, especially with the seasonal changes, the impact compression characteristics of freeze-thawed granite samples are studied under four different states in this study, such as moisture content and temperature difference. There are five groups of rock samples in each case, and the details of the four cases are as follows:

(1) The compression characteristics of freeze-thawed samples in dry and normal temperature states.

After freeze-thaw treatment, granite samples are dried and then placed indoors at room temperature, finally the impact compression test is carried out by using SHPB device (see Fig. 3).

(2) The compression characteristics of freeze-thawed samples in dry and frozen states.

After freeze-thaw treatment, granite samples are dried and then frozen in a thermostat held at $-30{ }^{\circ} \mathrm{C}$. When reaching the set-point temperature, samples are taken out from the freeze-thaw tester, and placed in the heat preservation container, and finally the impact compression test of frozen samples is carried out by using SHPB device.

(3) The compression characteristics of freeze-thawed samples in saturated and normal temperature states. 
After freeze-thaw treatment, granite samples are saturated in vacuum and soaked in water for $48 \mathrm{~h}$ to ensure their complete saturation, finally the impact compression test is carried out by using SHPB device.

(4) The compression characteristics of freeze-thawed samples in saturated and frozen states.

After freeze-thaw treatment, granite samples are saturated in vacuum and soaked in water for $48 \mathrm{~h}$ to ensure their complete saturation, and then frozen in a thermostat held at $-30{ }^{\circ} \mathrm{C}$. When reaching the set-point temperature, samples are taken out from the freeze-thaw tester, and placed in the heat preservation container, and finally the impact compression test of freeze-thawed samples is carried out by using SHPB device.

\section{Analysis of test results}

\subsection{Comparison of impact strength}

The impact compressive strength of each group of samples under different states is shown in Fig. 4, the gas pressure impact on samples is equal to $0.6 \mathrm{MPa}$. The four states of samples subjected to freeze-thaw treatment are described in Section 3. In the same state, the impact compressive strength decreases with the increase of freeze-thaw cycles, this is mainly due to the continuous migration and accumulation of water in rock samples caused by repeated freeze-thaw cycles, the frost heave stress repeatedly acting on rock pores and the uneven shrinkage and expansion of different mineral components, eventually leading to the growth of cracks and performance deterioration.

In addition, after 120 freeze-thaw cycles, the degradation degree of average impact strength of samples in four states is $20.17 \%, 25.93 \%, 31.22 \%$ and $39.17 \%$, respectively. It can be seen that 
196

197

although the number of freeze-thaw cycles is the same, the deterioration degree is different due to the different state (see Section 3) of granite samples. In this study, granite samples in saturated and frozen states display the greatest degree of degradation of average impact strength, while the degree of degradation is the least in dry and normal temperature states, moreover, the degree of degradation ranks second in the dry and frozen states, and it ranks third in saturated and normal temperature states. The possible reasons are as follows:

(1) In dry and normal temperature states, the internal microstructures of granite samples are filled with water, generally called pore water, which transfers compressive stress to crack tip and produces tensile stress when subjected to impact load, therefore, pore water plays an active role in crack growth, resulting in the decrease of compressive strength of granite samples. In addition, capillary pressure generally exists in the pores and plays a role in adhesively bonding mineral particles. However, the capillary pressure decreases with the increase of water content, when the pore is saturated with water, the crack tip may be in a tensile state of stress, which makes it easier to propagate. Water also weakens the properties of cementitious materials in rocks, which is also unfavorable to the impact strength.

(2) In the dry and frozen states, rock sample belongs to a single phase medium, the mineral particles contract when cooled, leading to the growth of cracks. On the other hand, when the rock is frozen, the bond strength decreases accordingly.

(3) In saturated and frozen states, the shrinkage of mineral particles and crystals leads to crack propagation, moreover, water turns into ice, resulting in an increase in volume, these two factors are unfavorable to the impact strength of samples. Moreover, the interaction between the shrinkage of mineral particles, crystals and the volume expansion of water causes strong tensile 
stress, and promotes crack propagation.

In order to study the relationship between impact strength and freeze-thaw cycles under the same weathering state, we take the freeze-thaw times as the independent variable and the impact compressive strength as the dependent variable, then Eq. (7) can be obtained.

$\sigma=a n^{2}+b n+c$

where $\sigma$ is impact compressive strength; $n$ is freeze thaw cycles; $a, b$ and $c$ are arbitrary coefficients, and the values are shown in Table 1.

The relationship between impact compressive strength and freeze thaw cycles is shown in Fig. 5, which further shows that although the conditions are different, the variation rules are similar. In dry and normal temperature states, the impact strength of granite samples is always the largest with the increase of freeze-thaw cycles. In saturated and frozen states, the impact strength of granite samples is always the minimum. Generally speaking, the impact strength of granite samples has the smallest dispersion in saturated and normal temperature states, and the largest dispersion in dry and normal temperature states. As the number of freeze-thaw cycles increases, the deceleration of impact strength gradually slows down, and showing that the slope of curves slightly decreases (see Fig. 5a, b and c), however, the deceleration of impact strength increases slowly in Fig. 5d, and showing that the slope of curves slightly increases.

\subsection{The stress-strain characteristics}

Fig. 6 shows the typical stress-strain curve of granite samples under impact load, the results depict that the stress-strain curve can be divided into elastic stage, yield stage and failure stage, and has no obvious compaction stage, and displays a linear increase state initially. In addition, after entering into the yield stage, the structures with lower strength in samples is initially cracked 
and destroyed, and leading to the damage of surrounding structure in high stress environment, then macro cracks are generated until the sample is destroyed.

It can be seen from Fig. 6a, b, c and d that the elastic modulus of granite gradually decreases with increase of freeze-thaw cycles. The reason may be that the frost heaving force compresses the pore structure, which leads to the initiation and growth of micro-cracks, resulting in the destruction of the internal structure. In addition, the repeated change of temperature $\left(-30{ }^{\circ} \mathrm{C},+\right.$ $20{ }^{\circ} \mathrm{C}$ ) leads to the continuous conversion of shrinkage and expansion of cementitious materials, resulting in the gradual deterioration of granite properties. Moreover, the dissolution and erosion of cementitious materials during the melting process also lead to the formation of cracks, therefore, the elastic modulus of granite decreases under the impact load, and the decreasing range increases with the increase of freeze-thaw cycles.

As shown in Fig. 7, the elastic modulus also shows obvious differences in different states under the same freeze-thaw cycles. Generally speaking, the elastic modulus of granite has maximum value in saturated and frozen states, except for the specimens without freeze-thaw cycles, and second largest value in saturated and normal temperature states. In addition, Fig. 7 also shows that the value of elastic modulus is relatively small in dry and normal temperature states as well as dry and frozen states. From a theoretical point of view, the minimum value of elastic modulus should be obtained in dry and normal temperature states, however, considering the discreteness of samples, the comparison of the values of elastic modulus given by the black and blue curves in Fig. 7 shows that the results are a little different from the theory. In a word, the possible reasons are as follows:

(1) Water expands when it freezes, and the mineral particles shrink when cooled, leading to 
crack propagation and strength degradation. In saturated and frozen states, micro-cracks have become incompressible due to the existence of ice, the crack propagates directly without compaction under impact load, so the strain before failure is relatively small, and the elastic modulus becomes larger.

(2) In saturated and normal temperature states, cracks are filled with water which plays a positive role in crack initiation, leading to the deterioration of mechanical properties of granite samples. When subjected to impact load, micro-cracks have become difficult to close due to the existence of water, and propagate directly, therefore, samples are destroyed without larger strain. However, a small amount of water will overflow under impact load, so the elastic modulus is still lower than that in saturated and frozen states.

(3) In dry and normal temperature states, there is no water in micro-cracks which can be compressed under impact load, therefore, the deformation is relatively larger, resulting in a smaller elastic modulus.

(4) In dry and frozen states, low temperature reduces the cohesion of the internal structure of granite samples and increases its brittleness, compared with the dry and normal temperature state, the granite sample is relatively difficult to deform and more prone to brittle failure under the same load condition.

4.3 Influence analysis of freeze thaw cycles

Four different states are considered to study the effect of freeze-thaw cycles on the mechanical properties of granite samples, in this section, the freeze-thaw influence factors are proposed to characterize the influence of degree of freeze-thaw cycles, as shown in Eq. (8). $\omega=\frac{\sigma_{0}-\sigma_{n}}{n}$ 
where $\omega$ is the freeze-thaw influence factors; $\sigma_{0}$ is the impact compressive strength of rock samples without freeze-thaw cycles; $\sigma_{n}$ is the impact compressive strength of rock samples after the nth freeze-thaw cycle; $n$ is the number of freeze-thaw cycles.

According to Eq. (8), the freeze-thaw influence factors of granite samples in four different states are shown in Fig. 8. The results show that the freeze-thaw influence factor has the maximum value in saturated and frozen states, and the minimum value in dry and normal temperature states.

One of the reasons may be that, as the increase of freeze-thaw cycles, the damage of rock pore structures increases gradually, if the pore structures are filled with medium, such as water, ice etc, the crack propagation is promoted when subjected to impact load, the degree of deterioration of impact strength increases with increase of porosity. It can also be seen from Fig. 8 that the freeze-thaw influence factor in dry and frozen states is larger than that in dry and normal temperature states, this is mainly due to the increase of porosity caused by freeze-thaw cycles, leading to the increase of shrinkage of mineral particles when cooled, therefore, the impact strength decreases correspondingly and the freeze-thaw influence factor becomes larger. Finally, it can be concluded that water and low temperature improve the effect of freeze-thaw cycles on the dynamic mechanical properties of granite samples in this study.

\section{Conclusions}

The impact strength of granite samples deteriorates with the increase of freeze-thaw cycles in the same state. For samples in different states, although the number of freeze-thaw cycles is equal, the degree of deterioration of the impact strength is different. The stress-strain curves of granite 
samples are generally similar to each other in four different states, there is no obvious compaction stage of micro-cracks, and the curves directly enter into the elastic, yield and failure stages.

For granite samples in the same state, when subjected to impact load, the dynamic elastic modulus decreases with the increase of freeze-thaw cycles, however, the degree of decrease is different for different states. Under the same freeze-thaw cycles, the dynamic elastic modulus from large to small is generally as follows: samples in saturated and frozen states, samples in saturated and normal temperature states, samples in dry and frozen states and samples in dry and normal temperature states.

Under the same freeze-thaw cycles, the results show that the deterioration of mechanical properties of granite samples is different in four different weather states, and the order of the freeze-thaw influence factors from large to small is as follows: samples in saturated and frozen states, samples in saturated and normal temperature states, samples in dry and frozen states as well as samples in dry and normal temperature states. Therefore, water and low temperature improve the effect of freeze-thaw cycles on the dynamic mechanical properties of granite samples.

\section{Credit authorship contribution statement}

Bo Ke: Conceptualization, Methodology, Resources, Data curation, Writing - original draft, Funding acquisition. Chuanju Liu: Investigation, Writing - review \& editing, Data curation. Chunyang Zhang: Conceptualization, Methodology, Resources, Writing - review \& editing, Funding acquisition. Linmin Ding: Conceptualization, Methodology, Resources, Writing - review \& editing. Yixian Wang: Methodology, Writing - review \& editing, Funding acquisition. Hang Lin: Investigation, Writing - review \& editing, Data curation. 


\section{Declaration of Competing Interest}

The authors declared that there is no conflict of interest.

\section{Acknowledgements}

This paper gets its funding from Project (Grant NO. Z020015) supported by Open Research Fund of State Key Laboratory of Geomechanics and Geotechnical Engineering, Institute of Rock and Soil Mechanics, Chinese Academy of Sciences; Project (Grant NO. 42077249) supported by National Natural Science Foundation of China. The authors wish to acknowledge these supports.

\section{References}

Abdolghanizadeh K., Hosseini M., Saghafiyazdi M., 2020. Effect of freezing temperature and number of freezethaw cycles on mode I and mode II fracture toughness of sandstone. Theoretical and Applied Fracture Mechanics 105: Article ID 102428.

Cao R., Wang C., Yao R., Hu T., Lei D., Lin H., Zhao Y., 2020a. Effects of cyclic freeze-thaw treatments on the fracture characteristics of sandstone under different fracture modes: Laboratory testing. Theoretical and Applied Fracture Mechanics 109: Article ID 102738.

Cao R., Yao R., Hu T., Wang C., Li K., Meng J., 2020b. Failure and mechanical behavior of transversely isotropic rock under compression-shear tests: Laboratory testing and numerical simulation. Engineering Fracture Mechanics 241: Article ID 107389.

Cao R., Yao R., Meng J., Lin Q., Lin H., Li S., 2020c. Failure mechanism of non-persistent jointed rock-like specimens under uniaxial loading: Laboratory testing. International Journal of Rock Mechanics and Mining 
Çelik M.Y., 2017. Water absorption and P-wave velocity changes during freeze-thaw weathering process of crosscut travertine rocks. Environmental Earth Sciences 76: Article ID 409.

Deprez M., De Kock T., De Schutter G., Cnudde V., 2020a. A review on freeze-thaw action and weathering of rocks. Earth-Science Reviews 203: Article ID 103143.

Deprez M., De Kock T., De Schutter G., Cnudde V., 2020b. The role of ink-bottle pores in freeze-thaw damage of oolithic limestone. Construction and Building Materials 246: Article ID 118515.

Ding S., Jia H., Zi F., Dong Y., Yao Y., 2020. Frost Damage in Tight Sandstone: Experimental Evaluation and Interpretation of Damage Mechanisms. Materials 13(20): Article ID 4617.

Fang X., Xu J., Wang P., 2018. Compressive failure characteristics of yellow sandstone subjected to the coupling effects of chemical corrosion and repeated freezing and thawing. Engineering Geology 233: 160-171. 
372

Hashemi M., Goudarzi M.B., Jamshidi A., 2018. Experimental investigation on the performance of Schmidt hammer test in durability assessment of carbonate building stones against freeze-thaw weathering. Environmental Earth Sciences 77: Article ID 684.

Hassan M., Wille K., 2017. Experimental impact analysis on ultra-high performance concrete (UHPC) for achieving stress equilibrium (SE) and constant strain rate (CSR) in Split Hopkinson pressure bar (SHPB) using pulse shaping technique. Construction and Building Materials 144:747-757.

Huang S., Lu Z., Ye Z., Xin Z., 2020. An elastoplastic model of frost deformation for the porous rock under freeze-thaw. Engineering Geology 278: Article ID 105820.

Ivankina T.I., Zel I.Y., Petruzalek M., Rodkin M.V., Matveev M.A., Lokajicek T., 2020. Elastic anisotropy, permeability, and freeze-thaw cycling of rapakivi granite. International Journal of Rock Mechanics and Mining Sciences 136: Article ID 104541.

Jia H., Ding S., Zi F., Dong Y., Shen Y., 2020. Evolution in sandstone pore structures with freeze-thaw cycling and interpretation of damage mechanisms in saturated porous rocks. Catena 195, Article ID 104915.

Jia S.Q., Wang F.S., Zhou J.J., Jiang Z.P., Xu B., 2021. Study on the mechanical performances of carbon fiber/epoxy composite material subjected to dynamical compression and high temperature loads. Composite Structures 258: Article ID 113421.

Ke B., Zhang J., Deng H., Yang X., 2020. Dynamic Characteristics of Sandstone under Coupled Static-Dynamic Loads after Freeze-Thaw Cycles. Applied Sciences 10: Article ID 3351.

Ke B., Zhou K., Xu C., Deng H., Li J., Bin F., 2018. Dynamic Mechanical Property Deterioration Model of Sandstone Caused by Freeze-Thaw Weathering. Rock Mechanics and Rock Engineering 51: 2791-2804.

Kellerer-Pirklbauer A., 2017. Potential weathering by freeze-thaw action in alpine rocks in the European Alps during a nine year monitoring period. Geomorphology 296: 113-131. 
394 79: 2021-2036. 305.

Langman J.B., Blowes D.W., Amos R.T., Atherton C., Wilson D., Smith L., Sego D.C., Sinclair S.A., 2017. Influence of a tundra freeze-thaw cycle on sulfide oxidation and metal leaching in a low sulfur, granitic waste rock. Applied Geochemistry 76: 9-21.

Li K., Li M., Zhang D., Liu C., Ma D., 2020. Effect of Moisture Content on Bursting Liability of Sandstone due to Freeze-Thaw Action. Shock and Vibration 2020: Article ID 8832528.

Lin H., Lei D., Yong R., Jiang C., Du S., 2020a. Analytical and numerical analysis for frost heaving stress distribution within rock joints under freezing and thawing cycles. Environmental Earth Sciences 79(12): Article ID

Lin H., Lei D., Zhang C., Wang Y., Zhao Y., 2020b. Deterioration of non-persistent rock joints: A focus on impact of freeze-thaw cycles. International Journal of Rock Mechanics and Mining Sciences 135: Article ID 104515.

Lin H., Zhang X., Cao R., Wen Z., 2020c. Improved nonlinear Burgers shear creep model based on the time-dependent shear strength for rock. Environmental Earth Sciences 79: Article ID 149.

Liu C., Deng H., Chen X., Xiao D., Li B., 2020a. Impact of rock samples size on the microstructural changes induced by freeze-thaw cycles. Rock Mechanics and Rock Engineering 53: 5293-5300.

Liu C., Wang D., Wang Z., Ke B., Li P., Yu S., 2021. Dynamic splitting tensile test of granite under freeze-thaw weathering. Soil Dynamics and Earthquake Engineering 140: Article ID 106411.

Liu T., Zhang C., Cao P., Zhou K., 2020b. Freeze-thaw damage evolution of fractured rock mass using nuclear magnetic resonance technology. Cold Regions Science and Technology 170: Article ID 102951.

Liu Y., Cai Y., Huang S., Guo Y., Liu G., 2020c. Effect of water saturation on uniaxial compressive strength and damage degree of clay-bearing sandstone under freeze-thaw. Bulletin of Engineering Geology and the Environment

Lu Y., Li X., Han Y., Wu J., 2021. Mechanical properties of rock samples with a single natural weak plane after 
418 Thermal Cycling on the Dynamic Tensile Strength of Granitic Rocks. Rock Mechanics and Rock Engineering

Mousavi S.Z.S., Tavakoli H., Moarefvand P., Rezaei M., 2020. Micro-structural, petro-graphical and mechanical 103039. regions under freeze-thaw weathering cycles based on NMR. Geofluids 2020: Article ID 8849444.

Pápay Z., Török Á., 2015. Effect of Thermal and Freeze-thaw Stress on the Mechanical Properties of Porous 
considering different temperature ranges. Bulletin of Engineering Geology and the Environment 80: 2349-2366.

Wang F.Z., Liu S.Y., Cao L., 2020a. Research on dynamic compressive behaviors of marble under high strain rates with split Hopkinson pressure bar. Journal of Structural Geology 138: Article ID 104095.

Wang P., Xu J., Fang X., Wang P., Zheng G., Wen M., 2017. Ultrasonic time-frequency method to evaluate the deterioration properties of rock suffered from freeze-thaw weathering. Cold Regions Science and Technology 143: $13-22$.

Wang P., Xu J., Liu S., Wang H., Liu S., 2016. Static and dynamic mechanical properties of sedimentary rock after freeze-thaw or thermal shock weathering. Engineering Geology 210: 148-157.

Wang Y., Feng W., Wang H., Han J., Li C., 2019. Geomechanical and Acoustic Properties of Intact Granite Subjected to Freeze-Thaw Cycles during Water-Ice Phase Transformation in Beizhan's Open Pit Mine Slope, Xinjiang, China. Water 11(11): Article ID 2309.

Wang Y., Gao S.H., Li C.H., Han J.Q., 2021b. Energy dissipation and damage evolution for dynamic fracture of marble subjected to freeze-thaw and multiple level compressive fatigue loading. International Journal of Fatigue 142: Article ID 105927.

Wang Y., Han J.Q., Li C.H., 2020b. Acoustic emission and CT investigation on fracture evolution of granite containing two flaws subjected to freeze-thaw and cyclic uniaxial increasing-amplitude loading conditions. Construction and Building Materials 260: 119769.

Xiao Y., Li C., Cao J., Wang Y., Hou Z., Hu N., 2020. Investigation of the Effects of Freeze-Thaw Cycles on Geomechanical and Acoustic Characteristics of Tuff Specimens under Different Stress Paths. Advances in Civil Engineering 2020: Article ID 6689181.

Xie Y.J., Fu Q., Zheng K.R., Yuan Q., Song H., 2014. Dynamic mechanical properties of cement and asphalt mortar based on SHPB test. Construction and Building Materials 70:217-225. 
Yang X., Jiang A., Zhang F., 2021b. Research on creep characteristics and variable parameter-based creep damage constitutive model of gneiss subjected to freeze-thaw cycles. Environmental Earth Sciences 80: Article ID 7. 252-264. 
Cold-Region Tunnels. Advances in Civil Engineering 2020: Article ID 6654778.

Zhao H., Zhang X., Han G., Chen H., 2019. Experimental investigation on the physical and mechanical properties deterioration of oil shale subjected to freeze-thaw cycles. Arabian Journal of Geosciences 12: Article ID 531.

Zhao Y.L., Zhang C.S., Wang Y.X., Lin H., 2020a. Shear-related roughness classification and strength model of natural rock joint based on fuzzy comprehensive evaluation. International Journal of Rock Mechanics and Mining Sciences 137: Article ID 104550.

Zhao Y.L., Zhang L.Y., Liao J., Wang W.J., Liu Q., Tang L., 2020b. Experimental study of fracture toughness and subcritical crack growth of three rocks under different environments. International Journal of Geomechanics 20(8): Article ID 04020128.

Zheng Y., Chen C., Meng F., Liu T., Xia K., 2020a. Assessing the stability of rock slopes with respect to flexural toppling failure using a limit equilibrium model and genetic algorithm. Computers and Geotechnics 124: Article ID 103619.

Zheng Y., Chen C., Meng F., Zhang H.N., Xia K.Z., Chen X.B., 2020b. Assessing the Stability of Rock Slopes with Respect to Block-Flexure Toppling Failure Using a Force-Transfer Model and Genetic Algorithm. Rock Mechanics and Rock Engineering 53(8): 3433-3445.

Zhou K., Li B., Li, J., Deng H., Bin F., 2015. Microscopic damage and dynamic mechanical properties of rock under freeze-thaw environment. Transactions of Nonferrous Metals Society of China 25(4): 1254-1261.

Zhou X.P., Niu Y., Zhang J.Z., Shen X.C., Zheng Y., Berto F., 2018. Experimental study on effects of freeze-thaw fatigue damage on the cracking behaviors of sandstone containing two unparallel fissures. Fatigue \& Fracture of Engineering Materials \& Structures 42(6): 1322-1340.

Zhou Z., Zhan H., Hu J., Ren C., 2019. Characteristics of unloading creep of tuffaceous sandstone in east Tianshan tunnel under freeze-thaw cycles. Advances in Materials Science and Engineering 2019: Article ID 7547564. 
Figures

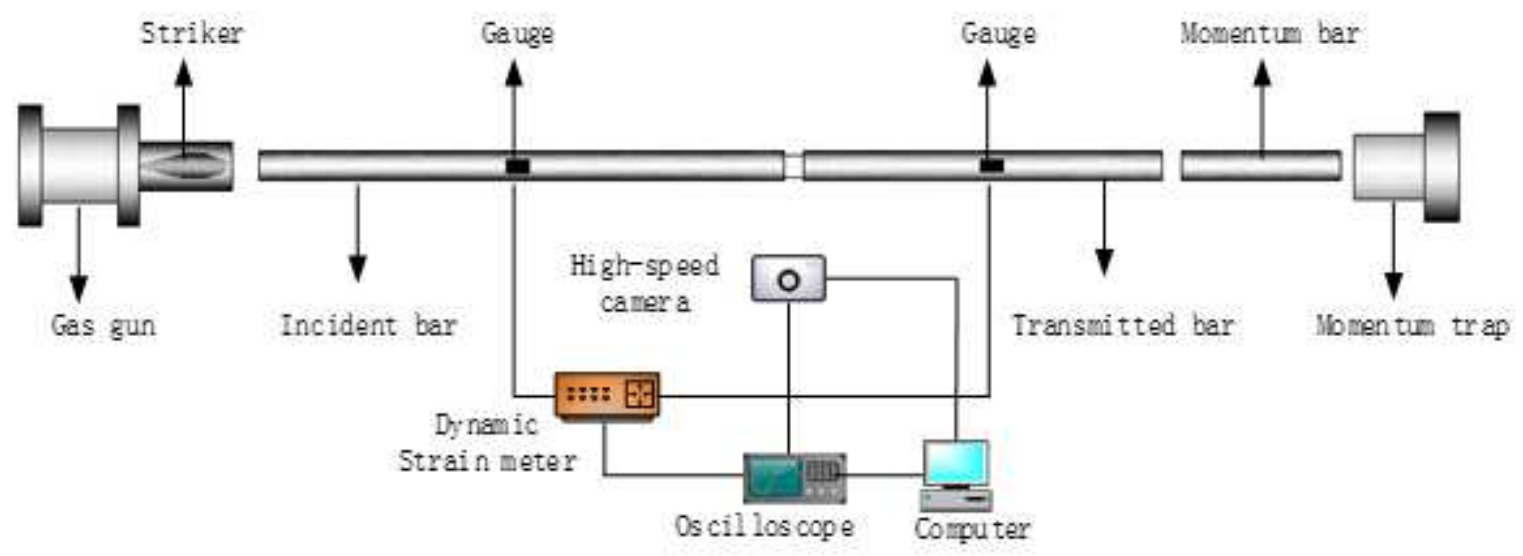

(a) The Composition of a SHPB device

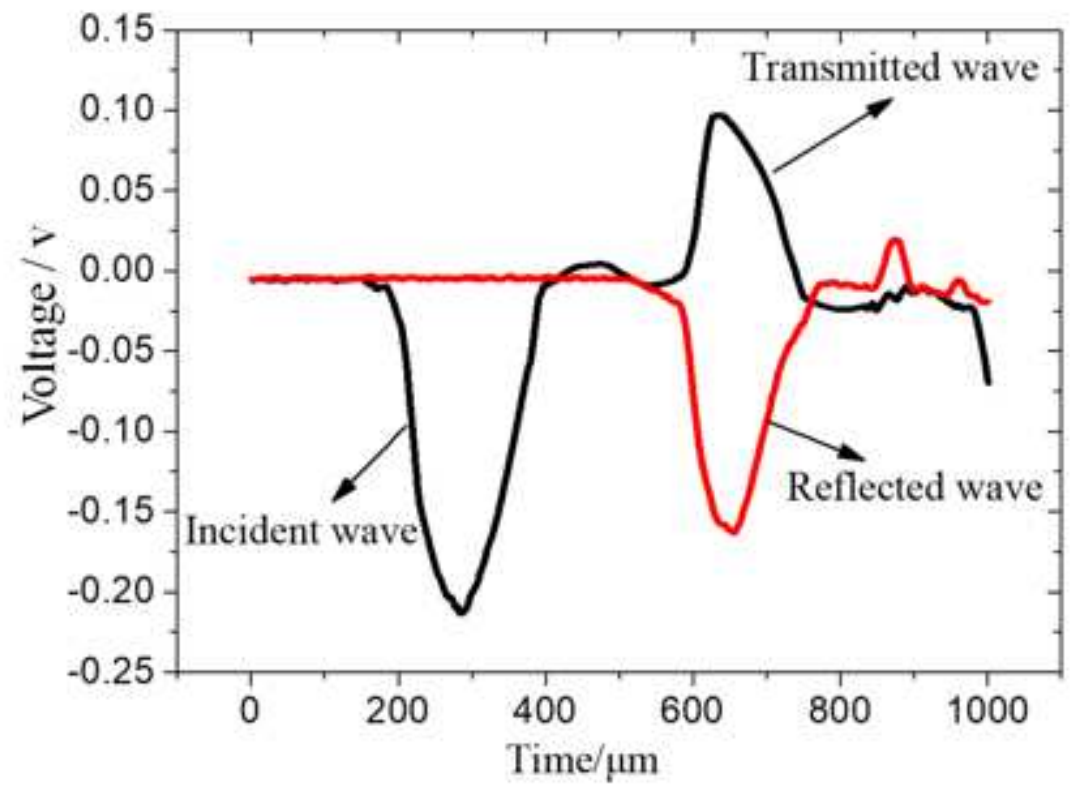

(b) The typical waveforms

Figure 1

Typical Split Hopkinson Pressure Bar (SHPB) device 


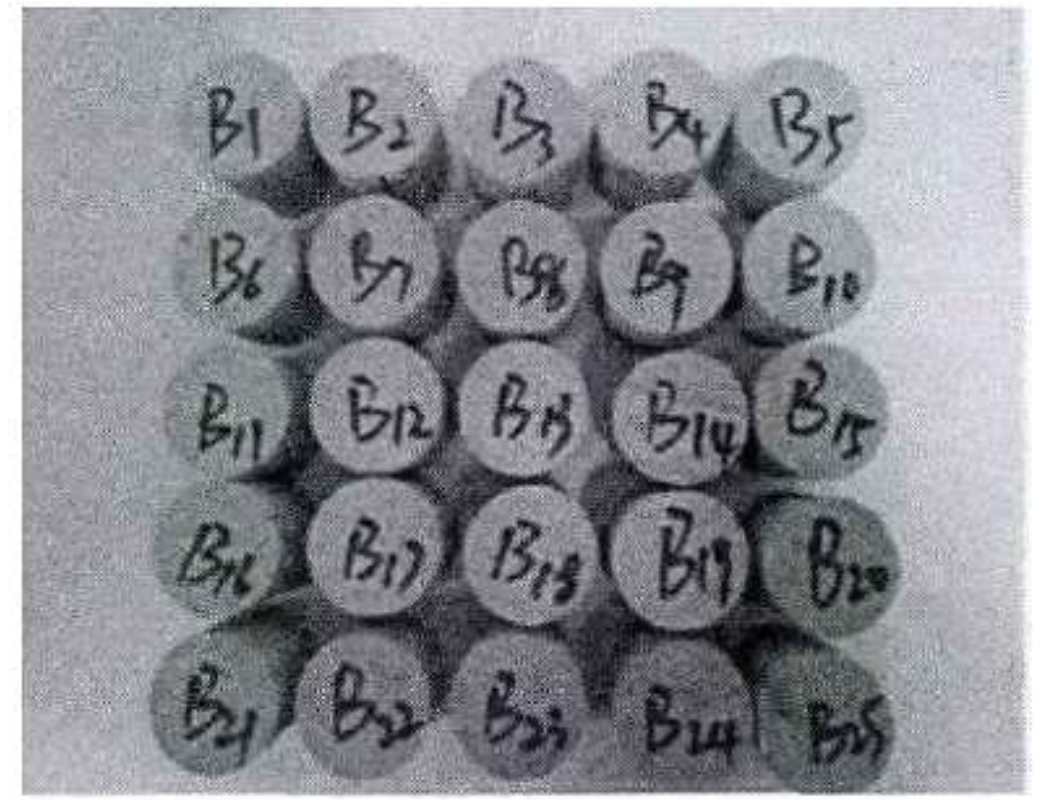

Figure 2

Typical granite samples

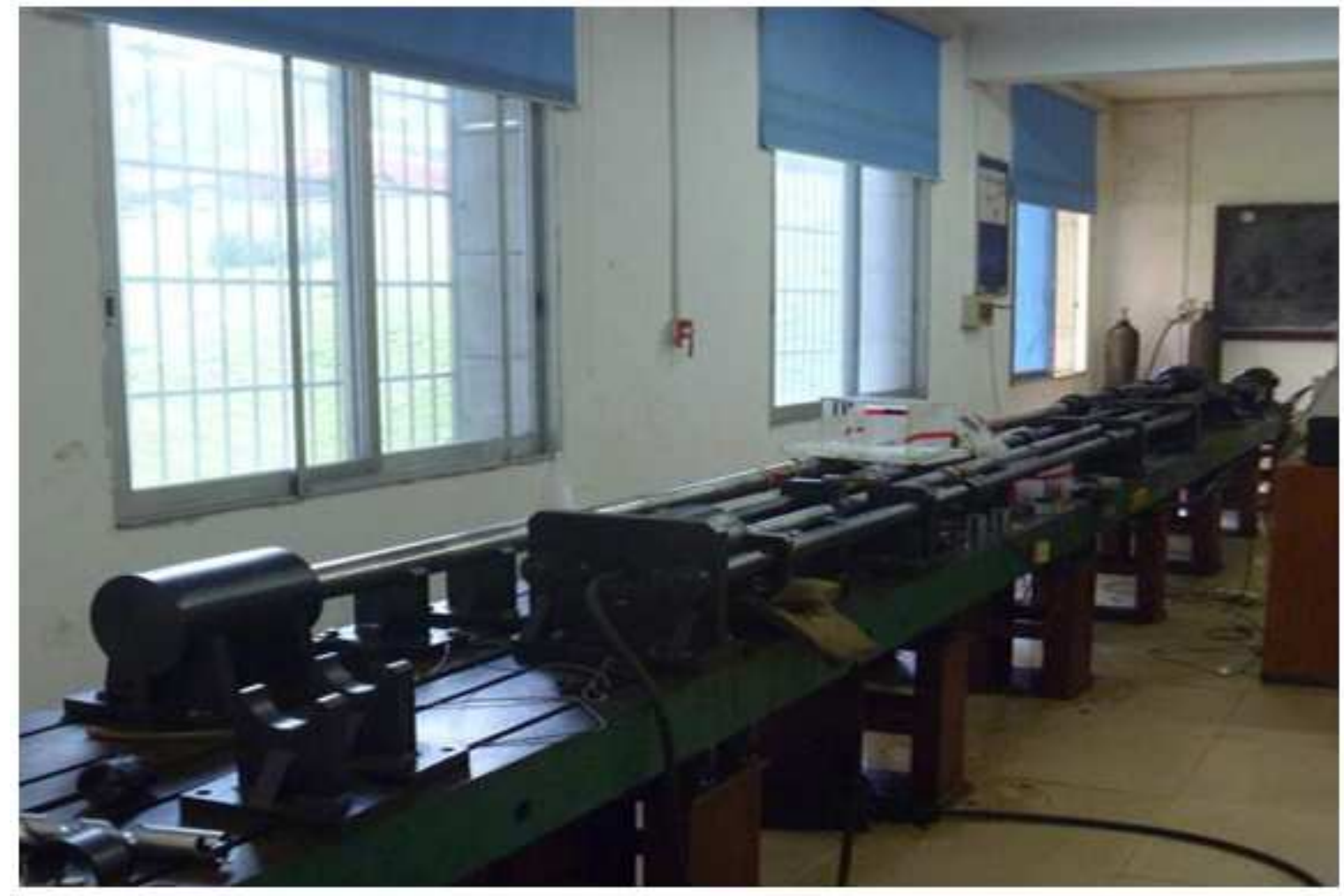

Figure 3

The split-Hopkinson pressure bar device in laboratory 


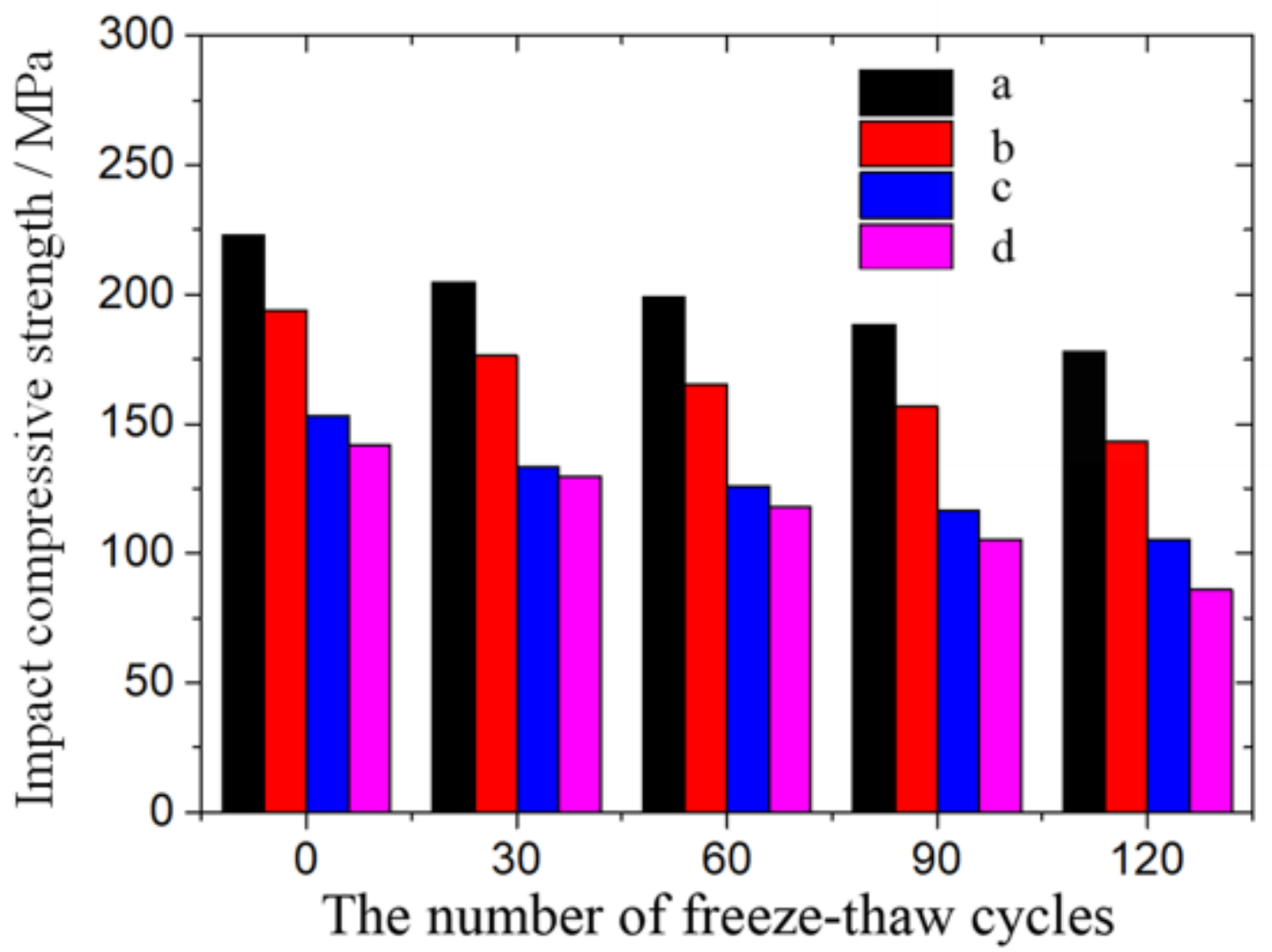

Figure 4

Average impact strength of each group of granite samples a. Dry and normal temperature states; $b$. Daturated and normal temperature states; c. Dry and frozen states; $d$. Saturated and frozen states. 


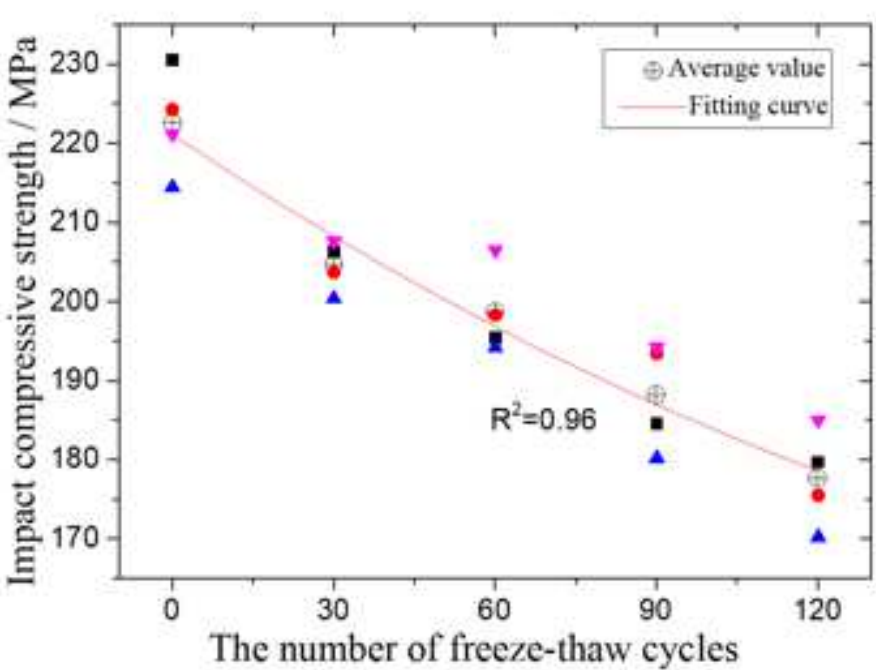

(a) Dry and normal temperature states

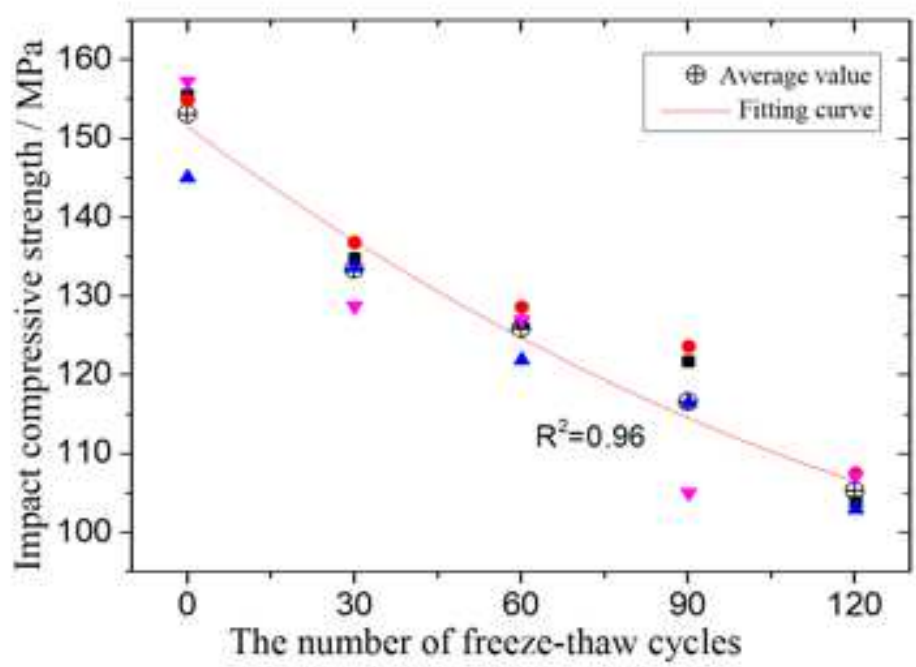

(c) Dry and frozen states

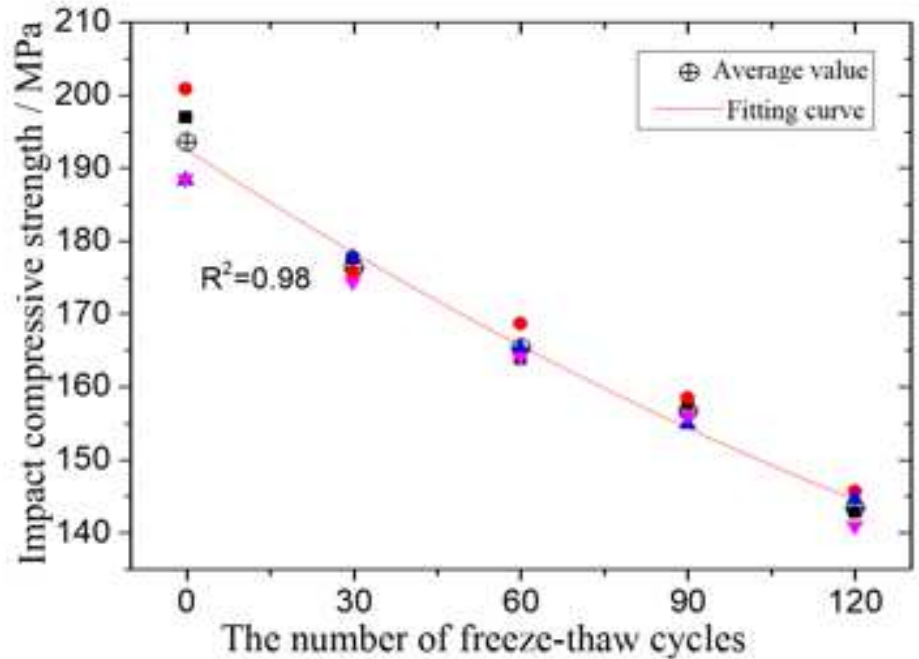

(b) Saturated and normal temperature states

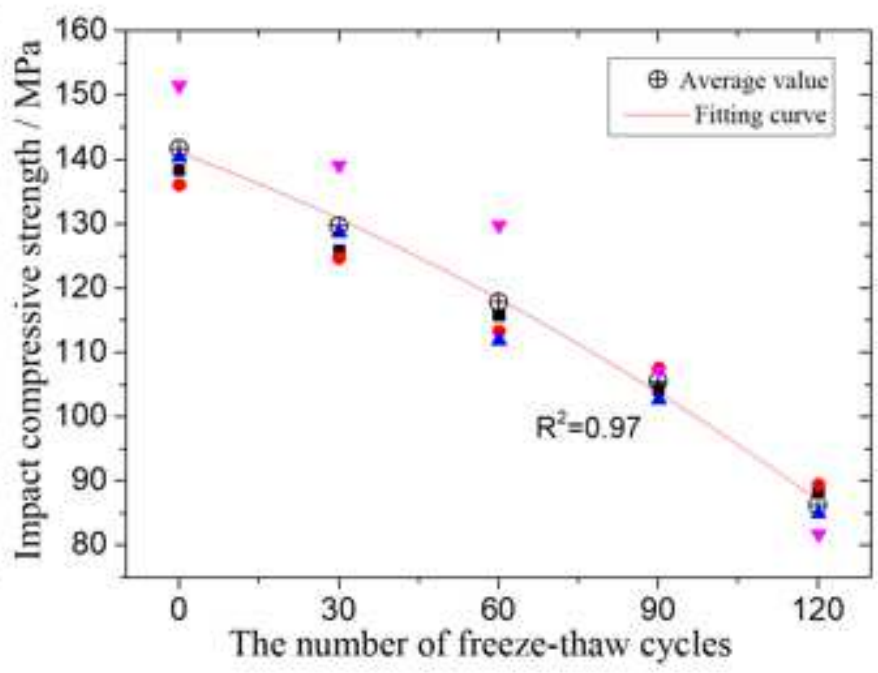

(d) Saturated and frozen states

\section{Figure 5}

The relationship between impact compressive strength and freeze thaw cycles 


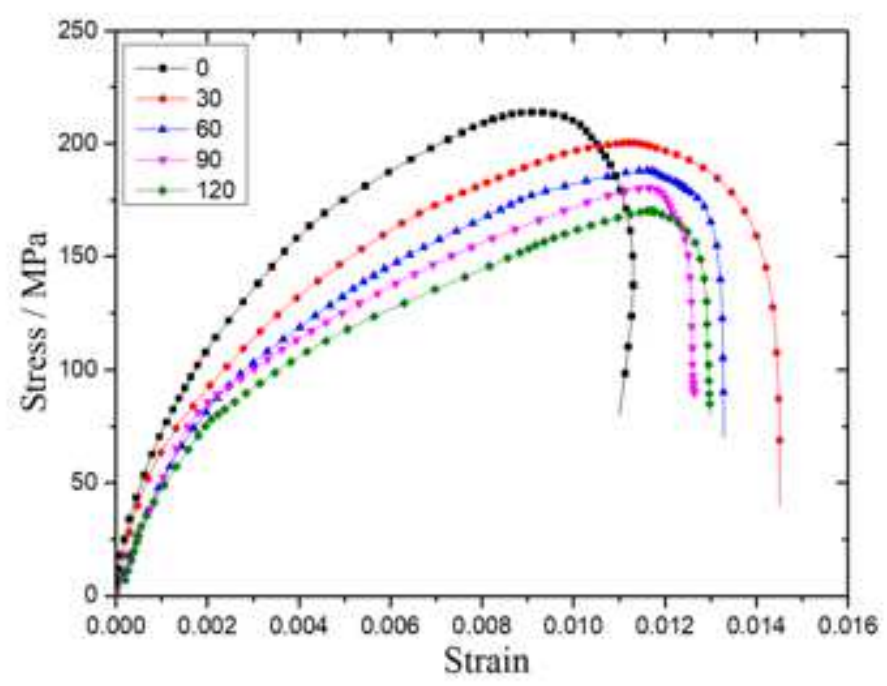

(a) Dry and normal temperature states

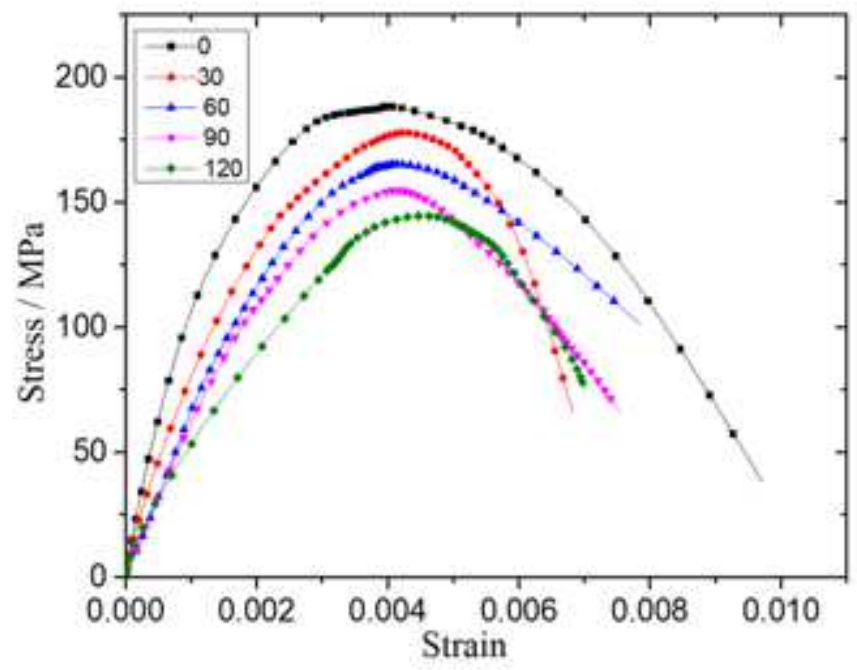

(c) Dry and frozen states

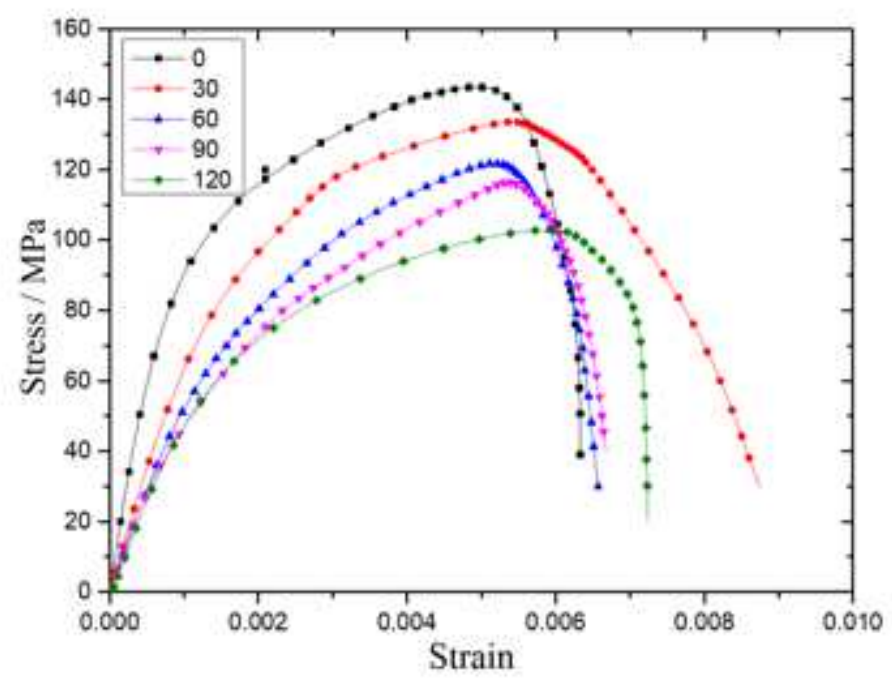

(b) Saturated and normal temperature states

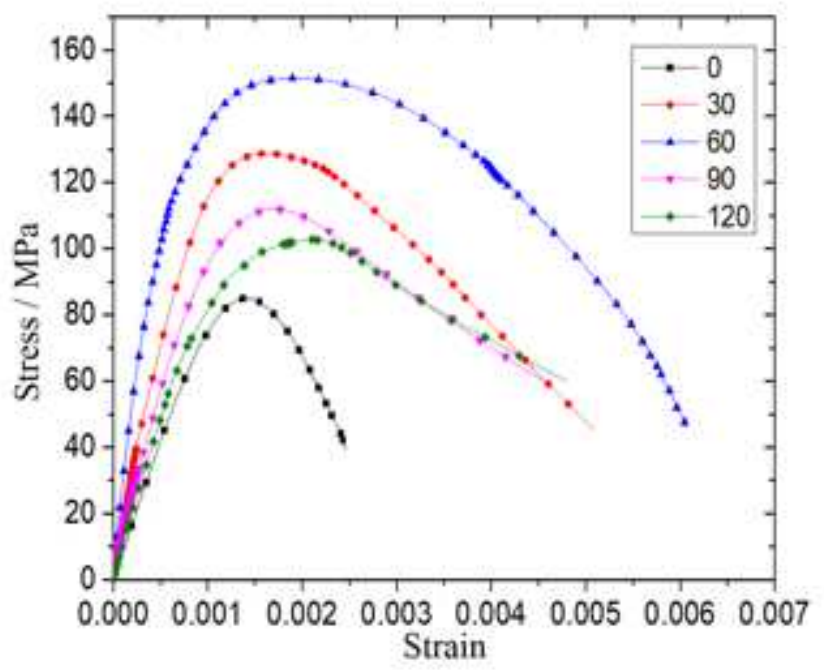

(d) Saturated and frozen states

Figure 6

The typical stress-strain curve of granite samples under impact load 


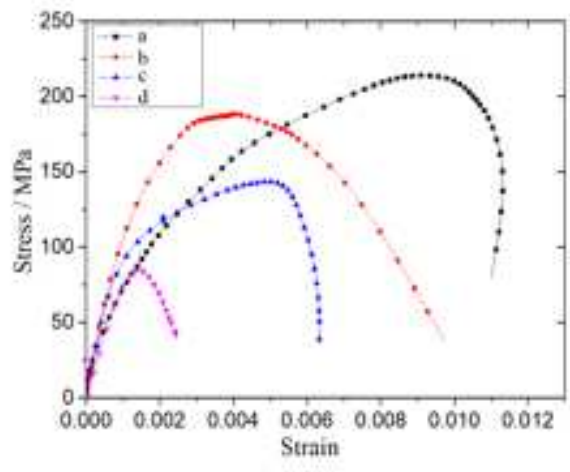

(a) The Oth freeze-thaw cycle

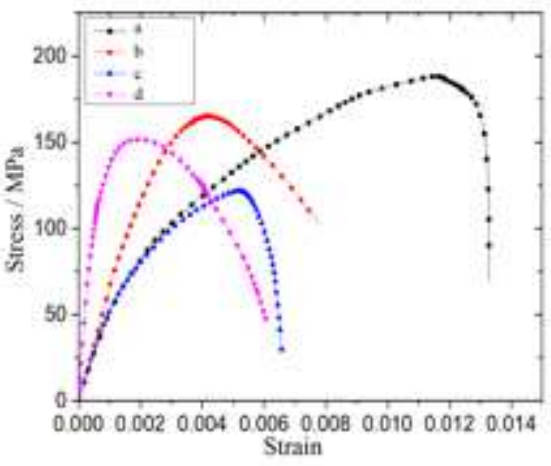

(c) The 60th freeze-thaw cycle

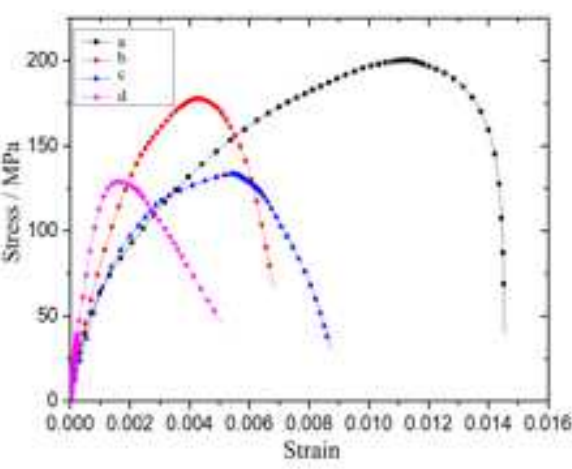

(b) The 30th freeze-thaw cycle

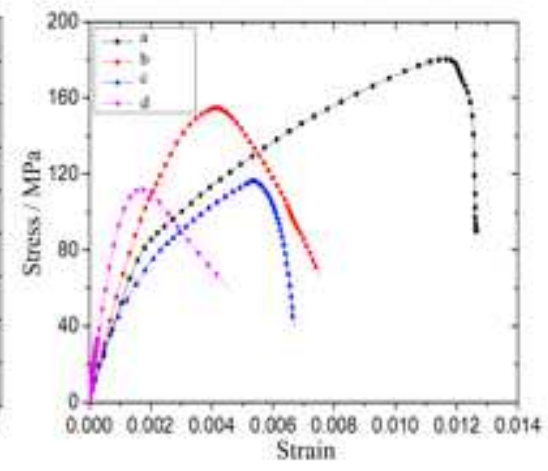

(d) The 90th freeze-thaw cycle

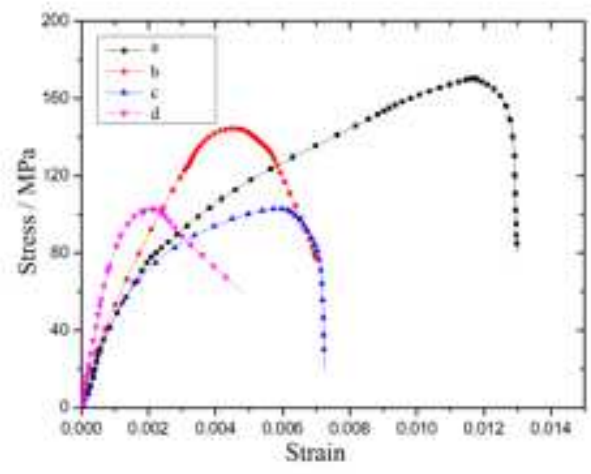

(e) The 120 th freeze-thaw cycle

\section{Figure 7}

The stress-strain curves of granite samples under different freeze-thaw cycles a. Dry and normal temperature states; b. Daturated and normal temperature states; c. Dry and frozen states; d. Saturated and frozen states. 


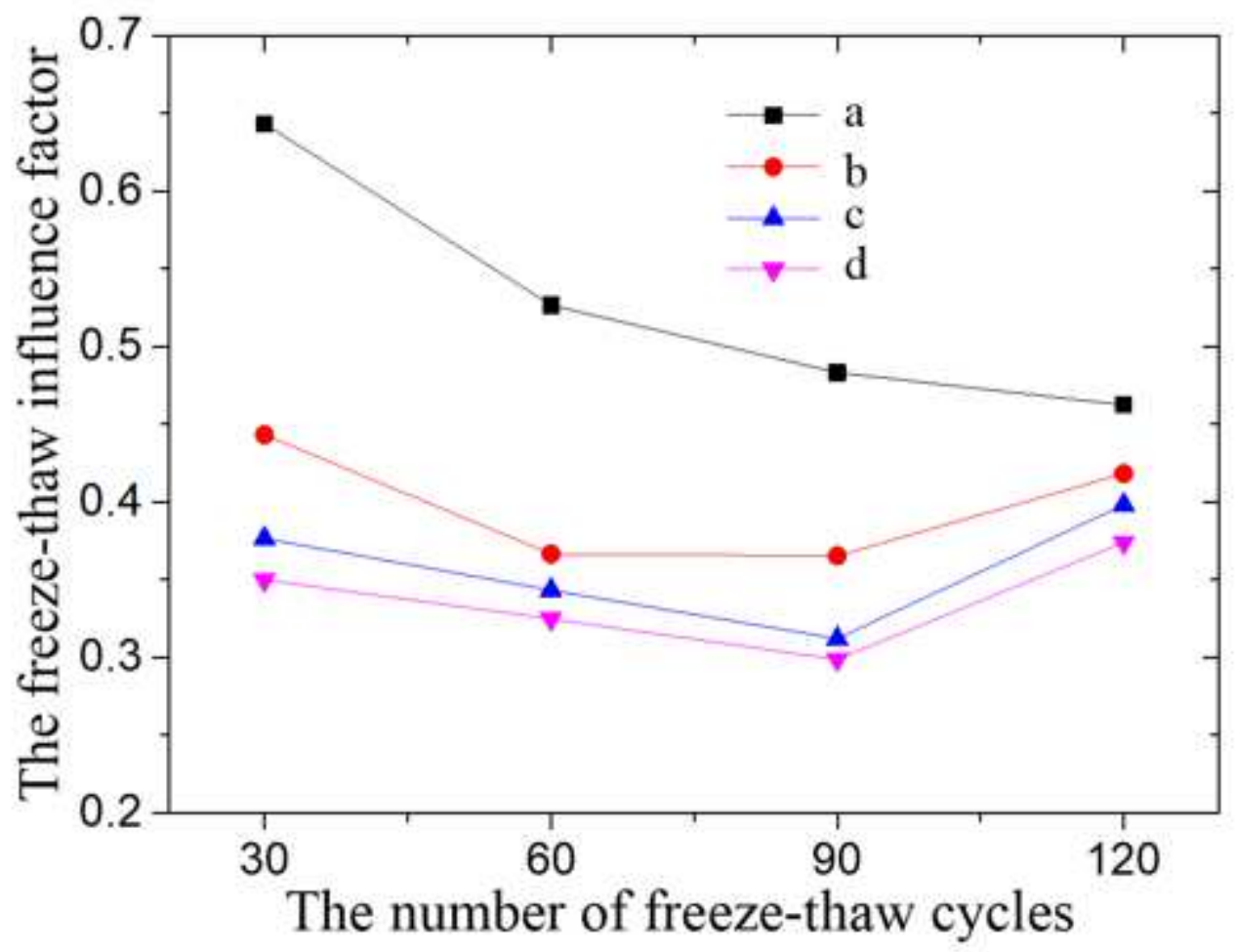

Figure 8

The freeze-thaw influence factors of freeze-thawed granite samples considering four different states a. Saturated and frozen states; b. Saturated and normal temperature states; c. Dry and frozen states; d. Dry and normal temperature states. 